\title{
Urticarial eruption in COVID-19-positive children: A report of two cases
}

\section{Shikhar Ganjoo', Resham Vasani²,3, Tulika Gupta ${ }^{4}$}

${ }^{1}$ Associate Professor, Department of Dermatology, Shree Guru Gobind Singh Tricentenary Medical College and Research Institute, Gurugram, India, ${ }^{2}$ Consultant Dermatologist, Bhojani Clinic, Matunga, Mumbai, India, ${ }^{3}$ Department of Pediatric Dermatology, B J Wadia Hospital for Children, Mumbai, India, ${ }^{4}$ Department of Ophthalmology, Sree Guru Gobind Singh Tricentenary Medical College \& Research Centre, Gurugram, India

Corresponding author: Shikhar Ganjoo, MD, E-mail: shikhar.ganjoo@gmail.com

\begin{abstract}
Recent literature has reported a variety of dermatological manifestations in children and adults associated with COVID-19. Herein, we report urticarial eruptions in two COVID-19-positive children. In the first case, urticaria with angioedema preceded a febrile episode and only partially responded to conventional doses of antihistamines. In the second case, urticaria followed the appearance of fever and upper respiratory symptoms. Both cases recovered completely within two weeks of diagnosis. These cases demonstrate that urticaria and angioedema, precedent or following a febrile illness, with or without respiratory symptoms, may be a presenting symptom of COVID-19 infection in children. A high index of suspicion in such cases helps the early administration of treatment and isolation of the patients to limit the spread of the virus.
\end{abstract}

Key words: COVID-19; Urticaria; RT-PCR

\section{INTRODUCTION}

Coronavirus disease 2019 (COVID-19), an infectious disease caused by severe acute respiratory syndrome coronavirus 2 (SARS-CoV-2), has rapidly emerged as an international public health problem. Viral infections are one of the potential triggers for urticaria and sometimes are the main etiological agents in acute and chronic forms of urticaria. In this article, we report two cases of urticarial eruptions in COVID-19-positive children.

\section{CASE REPORTS}

\section{Case 1}

A two-year-old female presented to us with a five-day history of pruritic, erythematous, evanescent rashes over the body. Hives first appeared on the soles, progressed to involve the trunk, and then assumed a generalized distribution. The progression of the lesions was associated with swelling of the lips and eyelids. On day five of the rash, the patient developed fever without chills, rigors, or upper respiratory tract symptoms. There was no preceding drug intake, known allergies, or a history of similar eruptions. There was no significant past, personal, or family history. There was no COVID-19-positive contact in the family.

An examination revealed multiple wheals, varying in size from $2 \mathrm{~cm}$ to $8 \mathrm{~cm}$, present symmetrically on the palms, soles, arms, legs, and trunk (Fig. 1). Angioedema involving the periorbital area and lips was present. Urticaria only partially responded to hydroxyzine $(0.6 \mathrm{mg} / \mathrm{kg}$ of body weight) only to relapse before the next dose scheduled. In addition, she received azithromycin $(10 \mathrm{mg} / \mathrm{kg}$ of body weight/day) for five days. Baseline blood tests showed leukocytosis $\left(17,600 / \mathrm{mm}^{3}\right)$ with lymphopenia $(56 \%)$ and raised C-reactive protein (2.09). Liver function and renal function tests, urine routine, and stool examination were within normal limits.

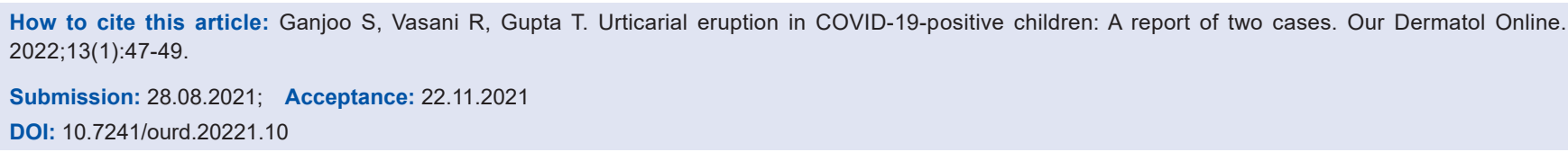




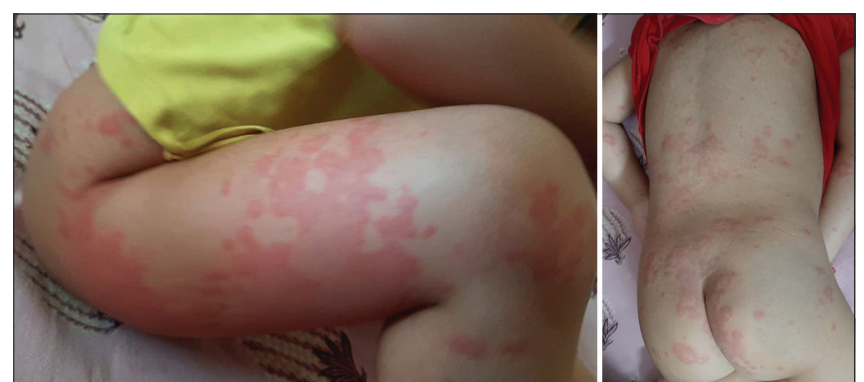

Figure 1: Clinical photograph of the child showing multiple urticarial wheals on the lower back, buttocks, thighs, and knees.

Considering the ongoing pandemic of COVID-19 with the background of a single episode of fever in a child presenting with urticaria, with blood investigations showing leukocytosis and lymphopenia, we advised a throat and nasal PCR swab for COVID-19, which was positive. The child was referred to a designated COVID-19 center, where she was treated with injectable ceftriaxone for two days, oral azithromycin was continued to complete five days, oral hydroxyzine $(0.6 \mathrm{mg} / \mathrm{kg}$ of body weight) with fexofenadine ( $3 \mathrm{mg} / \mathrm{kg}$ of body weight). The urticarial lesions resolved on day five of the admission, after which the antihistamines were withdrawn. The child was discharged ten days after the hospital admission, following negative RT-PCR. A follow-up of the patient for the next two months was uneventful and she showed no recurrence of the cutaneous symptoms.

\section{Case 2}

A five-year-old female presented to us with a three-day history of pruritic, erythematous, evanescent rashes over the body. These rashes appeared initially on the face and neck, and later progressed to involve the trunk. There was no associated angioedema. She had a history of high-grade fever without chills or rigors, which began two days before the onset of the rash and was associated with a runny nose. There was no history of drug intake prior to the appearance of the rash. There were no known allergies or similar symptoms in the past. The child had a history of COVID-19-positive contact in the family (grandfather).

An examination revealed multiple wheals on the face and trunk (Figs. 2a and 2b). Baseline blood tests revealed leukocytosis $\left(5,800 / \mathrm{mm}^{3}\right)$ with lymphopenia (40\%) and raised C-reactive protein (2.84). Liver function and renal function tests, urine routine, and stool examination of the patient were normal.

The child was started on levocetirizine $2.5 \mathrm{mg}$ daily along with oral amoxicillin and clavulanic acid for five

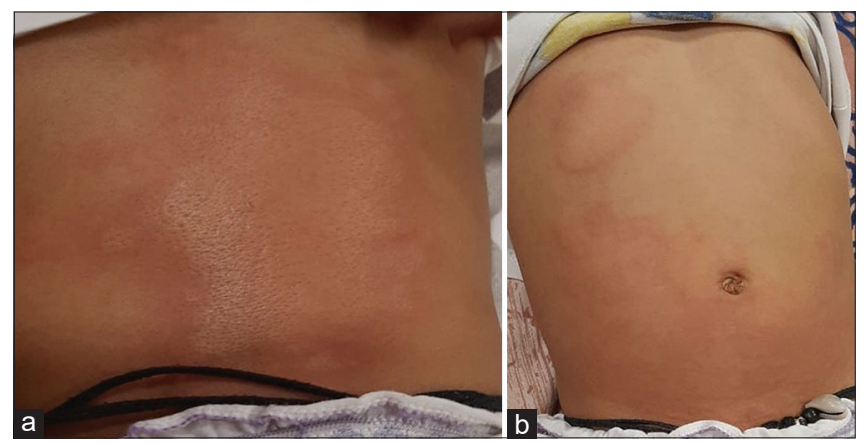

Figure 2: (a-b) Clinical photograph of the child showing urticarial wheals on the trunk (anterior and posterior aspects).

days. Since there was no response to the treatment at the end of five days, antigen-based testing for COVID-19 was performed, which was positive. She was advised strict home quarantine. Levocetirizine was increased to $2.5 \mathrm{mg}$ twice a day and continued for two weeks, after which urticaria subsided with no recurrences within two months.

\section{DISCUSSION}

Recent literature has demonstrated a variety of dermatologic manifestations among children and adults with COVID-19. Urticaria is a commonly reported finding. In a retrospective study by Zhang et al., $1.4 \%$ of patients had urticarial rashes [1]. In an Italian study by Recalcati et al., 18 out of 88 (20.5\%) patients had dermatological manifestations, among which three had widespread urticaria [2]. In a review by Tang et al., 88 out of $256(34.3 \%)$ patients across sixteen studies demonstrated dermatological manifestations, mostly as erythematous maculopapular rash, urticaria, or vesicular rash [3].

There is a paucity of reports available on cutaneous manifestations of COVID-19 in the pediatric age group. A majority of such manifestations in children have been found to be chilblain-like lesions or cutaneous acral lesions $[4,5]$. One case of urticarial eruption in a twomonth-old infant with COVID-19 has been reported [6].

In the first case, urticaria preceded fever and, in the second case, it appeared two days after the onset of fever, suggesting that urticaria in COVID-19 may be variable, with lesions appearing before, with, or after more than 48 hours of the onset of the fever. This is in opposition to a study by Galvan et al. which reported the appearance of urticarial lesions at the same time as other symptoms of the disease [7]. The authors also described urticarial and maculopapular lesions 
as associated with a more severe COVID-19 disease. However, no such association was found in either of our cases.

The appearance of urticarial lesions in the early phase of the disease suggests the direct role of SARS-CoV-2, entering the vascular tissue with angiotensin converting enzyme 2 protein inside the cells. The deposition of AgAb complexes on the site leads to complement activation and subsequent mast cell degranulation, leading to the onset of urticaria. Increased IL-6 levels in COVID-19 are also implicated in the pathogenesis of urticaria [8].

None of our two patients gave a history of drug intake prior to the urticarial episode, excluding a drug-induced etiology.

Our cases demonstrate that urticaria with pyrexia in a child may be the first manifestation of COVID-19 infection even with no respiratory symptoms. Given the current pandemic circumstances, a clinician should consider COVID-19 as a possible cause of urticaria, with or without angioedema, especially if the disease is unresponsive to the conventional doses of antihistamines. These patients may unknowingly infect others and contribute to the spread of the infection.

\section{CONSENT}

The examination of the patient was conducted according to the principles of the Declaration of Helsinki.

The authors certify that they have obtained all appropriate patient consent forms, in which the patients gave their consent for images and other clinical information to be included in the journal. The patients understand that their names and initials will not be published and due effort will be made to conceal their identity, but that anonymity cannot be guaranteed.

\section{REFERENCES}

1. Zhang JJ, Dong X, Cao YY, Yuan YD, Yang YB, Yan YQ, et al. Clinical characteristics of 140 patients infected with SARS-CoV-2 in Wuhan, China. Allergy. 2020;75:1730-41.

2. Recalcati S. Cutaneous manifestations in COVID-19: A first perspective. J Eur Acad Dermatol Venereol. 2020;34:e212-3.

3. Tang K, Wang Y, Zhang H, Zheng Q, Fang R, Sun Q. Cutaneous manifestations of the Coronavirus Disease 2019 (COVID-19): A brief review. Dermatol Ther. 2020;33:e13528.

4. Andina D, Noguera-Morel L, Bascuas-Arribas M, Gaitero-Tristán J, Alonso-Cadenas JA, Escalada-Pellitero S, et al. Chilblains in children in the setting of COVID-19 pandemic. Pediatr Dermatol. 2020;37:406-11.

5. Piccolo V, Neri I, Filippesch C. Chilblain-like lesions during COVID-19 epidemic: A preliminary study on 63 patients. J Eur Acad Dermatol Venereol. 2020:34;e291-3.

6. Morey-Olivé M, Espiau M, Mercadal-Hally M, Lera-Carballo E, García-Patos V. Cutaneous manifestations in the current pandemic of coronavirus infection disease (COVID 2019). An Pediatr (Engl Ed). 2020:92;374-5.

7. Galván Casas C, Català A, Carretero Hernández G, RodríguezJiménez P, Fernández-Nieto D, Rodríguez-Villa Lario A, et al. Classification of the cutaneous manifestations of COVID-19: A rapid prospective nationwide consensus study in Spain with 375 cases. Br J Dermatol. 2020;183:71-7.

8. Kaushik A, Parsad D, Kumaran M. Urticaria in the times of COVID-19. Dermatol Ther. 2020;33:e13817.

Copyright by Shikhar Ganjoo, et al. This is an open-access article distributed under the terms of the Creative Commons Attribution License, which permits unrestricted use, distribution, and reproduction in any medium, provided the original author and source are credited. Source of Support: Nil, Conflict of Interest: None declared. 